\title{
Letters
}

\section{Getting ethics into practice}

\section{Tuskegee was bad enough}

EDITOR-Parker wrote about getting medical ethics into practice. ${ }^{1}$ Atrocious as it was, the Tuskegee experiment as I understand it did not entail infecting anyone with syphilis. Rather, a group of poor and poorly educated African Americans (not prisoners) who had syphilis were left untreated and in some cases denied treatment for other intercurrent infections as well.

Tuskegee has cast a long shadow. Even today, conspiracy theories about the origins of HIV and AIDS may be best understood in terms of a legacy of mistrust about the motives of government health officials. Hence it is important not to spread further misinformation about this dark episode in the history of the US public health service.

Hilary Curtis freelance consultant on HIV/AIDS and sexual health

London NW6 7HF

hilary@regordane.net

Competing interests: None declared.

1 Parker MJ. Getting ethics into practice. BMJ 2004;329:126. (17 July.)

\section{Comparing Alder Hey with Tuskegee is not helpful}

EDITOR-I am troubled by the moral equivalence implied in the editorial by Parker, who refers to several high profile scandals that have occurred in medicine. ${ }^{1}$ Citing an instance where prisoners were deliberately infected with syphilis along with the Alder Hey matter raises a

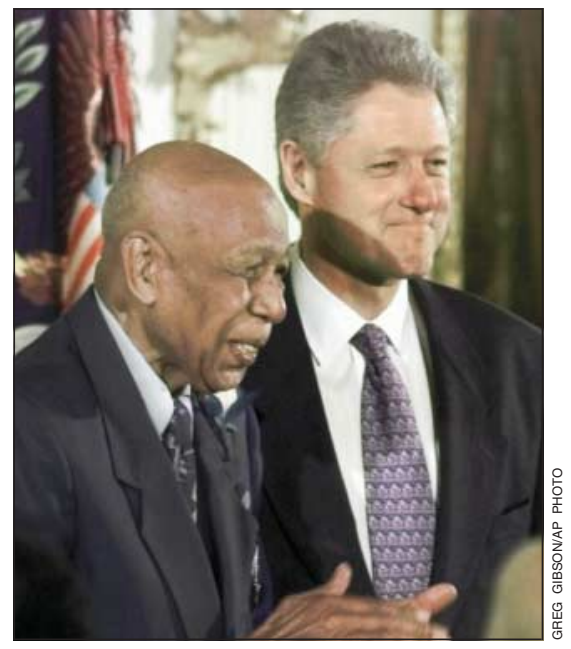

Remembering Tuskegee and making amends, 1997 very important point about the way in which moral and ethical issues are portrayed.

I agree that the Alder Hey matter was wrong, that it shouldn't have happened, and that numerous relatives were profoundly upset. However, I cannot accept that such a close moral and ethical comparison is made with the deliberate infection of live human beings in the way implied and that these two matters can be included in the same sentence. Readers are invited (wrongly, I believe) to make the connection, and this comparison adds further weight in the mind of the reader to the moral opprobrium that has attached to the Alder Hey issue.

This is, in other words, a journalistic device or trick that adds to the misery felt by the relatives-misery that has in some measure been created by expectations derived from ill informed and exaggerated comment by politicians and the media competing for attention. This has stifled research in an important field of medicine to the ultimate detriment of those and others whose emotions have been exploited.

Peter J Waugh medical inspector

Health and Safety Executive, East Grinstead, West Sussex RH19 3BE

znm33@dial.pipex.com

The views expressed are those of the author, not the Health and Safety Executive.

Competing interests: None declared.

1 Parker MJ. Getting ethics into practice. BMJ 2004;329:126. (17 July.)

\section{Ethics entails much common sense}

EDITOR-I agree with many of the points raised by Parker in his editorial. ${ }^{1}$ However, how far does one go? The position of "core" subjects in medical curriculums is increasingly tenuous, with the push to incorporate more and more peripheral (but nevertheless important) subjects. I am not aware of any evidence that formal training in medical ethics makes people any more ethical.

Furthermore, despite having an interest in medical ethics, being an expert member of a regional ethics committee, having had formal medicolegal training, and even having read Aristotle's Ethics from cover to cover, I find ethical issues and decisions just as difficult as always. In most situations where ethical considerations arise "on the shop floor," common sense and a sense of ease or unease (morality?) will guide most people in the right direction. Common sense is difficult to teach, and perhaps formal ethics training, despite playing a valuable part, may therefore not be as effective as we might think.

It may be more productive to involve "ethicists" more in day to day medicine, so that there is always someone on a bleep, such as a clinician with a special interest, who can give advice on ethical issues. Such input could then be integrated into everyday practice and be discussed, along with other issues such as morbidity and mortality, or audit, during monthly departmental meetings.

Kayvan Shokrollahi trust surgeon

Department of Plastic Surgery, Radcliffe Infirmary, Oxford OX2 6HE

kshokrollahi@lycos.com

Competing interests: $\mathrm{KS}$ is an expert member of the Oxfordshire Research Ethics Committee and a final year medical law student at the University of Northumbria.

1 Parker MJ. Getting ethics into practice. BMJ 2004;329:126. (17 July.)

\section{Author's reply}

EDITOR-I thank Curtis for identifying a factual mistake in the text. The Tuskegee study did not entail people being deliberately infected with syphilis: it was an observational study of 600 men, some of whom had syphilis. The study is often cited as an important example of unethical research practice because despite the discovery of an intervention for syphilis in the 1950 s (penicillin) the men in this study were not offered this treatment until the study came to an end in 1972. This was an editorial error. ${ }^{1}$

In response to Waugh, I mentioned both Alder Hey and Tuskegee in the editorial not because they are comparable in seriousness but because they are both examples of "scandals" in medicine that have led to a debate about ethics and ethical practice. I share Waugh's concerns about the subsequent reaction to the revelations about practice at Alder Hey, but this was not the focus of my editorial.

Michael J Parker reader in medical ethics University of Oxford, Oxford OX3 7LF michael.parker@ethox.ox.ac.uk

Competing interests: None declared.

1 Corrections and clarifications. BMJ 2004;329:384 (14 August.) 


\section{Future of psychotherapy in the NHS}

\section{Control groups play important part}

Editor-In discussing the future of psychotherapy, Goldbeck-Wood and Fonagy comment on the difficulties in providing meaningful evidence about efficacy. ${ }^{1}$ However, they do not explain that the specific problem is about the adequacy of control groups. ${ }^{2}$

Comparison of active with control treatment in psychotherapy cannot be conducted double blind as subjects inevitably know to which group they have been allocated. Drug trials may seem to have an advantage over psychotherapy trials in claims for scientific legitimacy because they can be conducted double blind by using placebo drugs. However, the degree of bias remaining in apparently double blind trials should not be underestimated. ${ }^{34}$

Goldbeck-Wood and Fonagy may have focused too much on evidence as factual without acknowledging the importance of interpretation and have therefore not spelt out the role of ideology in assessing efficacy. Evaluation of psychotherapy is controversial. Psychotherapy may be in conflict with biomedical psychiatry in its conceptualisation of mental illness. Moreover, statutory responsibilities under the Mental Health Act take precedence within mental health services over psychotherapy, which is a voluntary activity. Psychotherapy therefore struggles against the hegemony of biological psychiatry.

For reasons such as this, psychotherapy has established itself primarily outside the state sector, as Goldbeck-Wood and Fonagy note. Their solution is for the NHS to create a proper career structure for psychotherapists. Politically this may be less likely to be successful than taking advantage of the government policy for choice in the NHS. ${ }^{5}$ Primary care trusts need to look for alternative providers to meet the public demand for psychological therapies. Psychotherapists could organise themselves into provider organisations. These alternative providers should meet standards of training approved by such bodies as the UK Council for Psychotherapy and the British Confederation of Psychotherapists.

D B Double consultant psychiatrist

Carrobreck, Norfolk and Waveney Mental Health

Partnership NHS Trust, Hellesdon Hospital,

Norwich NR6 5BE

dbdouble@dbdouble.co.uk

Competing interests: None declared.

1 Goldbeck-Wood S, Fonagy P. The future of psychotherapy in the NHS: more evidence based services are taking shape to meet growing demand. BMJ 2004;329:245-6 (31 July.) 2 Bergin AE, Garfield S. Handbook of psychotherapy and behaviour change. 4th ed. New York: John Wiley, 1994 .

3 Fergusson D, Glass KC, Waring D, Shapiro S. Turning a Fergusson D, Glass KC, Waring D, Shapiro S. Turning a
blind eye: the success of blinding reported in a random sample of randomised, placebo controlled trials. $B M$ J 2004;328:432.

Moncrieff J, Double DB. Double blind random bluff. Men tal Health Today 2003:Nov:24-6.

Department of Health. Building on the best:choice, responsive-

Department of Health. Building on the best:choice,
ness and equity in the NHS. London: $\mathrm{DoH}, 2003$.
Psychotherapists require more than evidence based services to be recognised as professionals

EDITOR-Goldbeck-Wood and Fonagy said that one of the key obstacles for psychotherapy has been a conflict of cultures. ${ }^{1}$ Differences in the training of psychotherapists also have a key role in hindering the recognition of psychotherapy as an independent profession. In addition to the various modalities of psychotherapy, the huge variation in psychotherapists' training backgrounds makes it difficult for anyone to understand what they do.

A psychotherapist can be a counsellor, a social worker, a general practitioner, a clinical psychologist, or a psychiatrist. No mandatory training or regulatory bodies exist for psychotherapists in general, and the term is often used loosely, so anyone with little training can call himself or herself a psychotherapist. Moreover, who practises what kind of psychotherapy is also influenced by social and political factors. ${ }^{23} \mathrm{Pub}$ lic resources are more likely to be allocated to psychotherapy if an individual claim is made for a specific kind of psychotherapy and therapist, rather than using a general term.

Although "general practice psychotherapy" has previously been debated, it has now been accepted as a legitimate and important health service provided by the public health system in Canada. Similarly, in Australia, a recent initiative has given five incentives for general practitioners to engage in psychosocial counselling and brief psychotherapy strategies for patients, with publications and courses being offered to practitioners who are interested in becoming general practitioner psychotherapists. In the United States, with the influence of health management organisations, much psychotherapy is now conducted either by clinical psychologists or social workers to reduce costs. ${ }^{2}$ This is the only way towards governments in any country allowing healthcare money to be spent on psychotherapeutic treatments.

Samuel Y S Wong assistant professor $4 / F$

Department of Community and Family Medicine, Chinese University of Hong Kong, Hong Kong SAR, China

yeungshanwong@cuhk.edu.hk

\section{Competing interests: None declared.}

1 Goldbeck-Wood S. The future of psychotherapy in the NHS: more evidence based services are taking shape to meet growing demand. BMJ 2004;329:245-6. (31 July.) 2 Gabbard G, Kay J. The fate of integrated treatment: what ever happened to the biopsychosocial psychiatrist? $A m J$ Psychiatr 2001;158:1956-63.

3 Lieberman F. Psychotherapy and the clinical social worker Am J Psychiatr 1987;41:369-83.

\section{Arteriolar narrowing as predictor of hypertension}

Blood pressure and weight gain are better EDITOR-Wong et al studied the association between retinal vessel diameters and risk of hypertension. ${ }^{1}$ Some points would have deserved discussion.

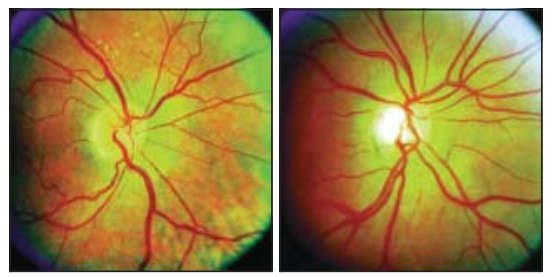

Narrowed (left) and normal (right) retinal arterioles

Firstly, evidence shows that blood pressure is one of the strongest predictors of the risk of progression towards hypertension. Thus, in the Framingham cohort study, ${ }^{2}$ subjects with a normal blood pressure (120129/80-84 $\mathrm{mm} \mathrm{Hg}$ ) had a twofold to fourfold increased risk of hypertension as subjects with optimum blood pressure (<120/80 mm Hg). Subjects with a high normal pressure (135-139/85-89 mm Hg) had fivefold to 12-fold raised odds. These figures were obtained only after four years of follow up. ${ }^{2}$

The odds ratios found by Wong et al were lower despite a longer follow up period. Moreover, with increasing retinal arteriole narrowing, the risk difference between normal and prehypertensive subjects disappeared. Do these findings indicate that, among patients in the first fourth of the arteriole-venule ratio, blood pressure is no longer a determinant of hypertension risk? This raises questions about the validity of the findings by Wong et al.

Secondly, again in the Framingham cohort study, the change in weight was a clear determinant of the risk of hypertension: a 5\% weight gain was associated with $20-30 \%$ increased odds of the incidence of hypertension. ${ }^{2}$ Weight change was not measured in the study by Wong et al. This change would have been a pertinent variable to consider for the multivariate analysis.

I am therefore not sure of the clinical pertinence of this study: before assessing arteriolar narrowing among my patients, I would prefer to measure their blood pressure carefully and to follow their change in weight to evaluate their risk of hypertension (and other health risks).

Arnaud Chiolero research fellow

Institut universitaire de médecine sociale et préventive, 1004 Lausanne, Switzerland arnaud.chiolero@hospvd.ch

Competing interests: None declared.

1 Wong TY, Shankar A, Klein R, Klein BE, Hubbard LD. Prospective cohort study of retinal vessel diameters and risk of hypertension. BMJ 2004;329:79-82. (10 July)

2 Vasan RS, Larson MG, Leip EP, Kannel WB, Levy D Assessment of frequency of progression to hypertension in non-hypertensive participants in the Framingham heart study: a cohort study. Lancet 2001;358:1682-6.

\section{Authors' reply}

EDITOR-Firstly, we agree that pre-existing blood pressure is an important predictor of overt hypertension. As in the Framingham study, ${ }^{1}$ our participants whose baseline blood pressure was classified as "prehypertensive" were more likely to develop clinical 
hypertension than those classified as "normal" (figure 2 in our paper). This effect was irrespective of retinal vessel diameters. However, direct comparison of incidence rates and odds ratios of hypertension between studies is always problematic because of differences in study population, methods, and analysis. For example, our multivariable models adjusted for baseline lipid concentrations, diabetes status, glycosylated haemoglobin concentrations, systolic and diastolic blood pressures, and pulse pressures, whereas the Framingham study adjusted only for age, sex, body mass index, and weight gain (table 5 of the Framingham study).

Secondly, as suggested, we conducted an additional multivariable analysis adjusting for weight change (change in body mass index between the baseline and 10 year follow up). The association of retinal arteriolar narrowing and risk of hypertension was essentially similar (odds ratio of $1.76,95 \%$ confidence intervals, 1.34-2.32, comparing lowest to highest arteriolevenule ratio).

Finally, the issue of clinical relevance was raised. We concur with Chiolero that carefully measuring blood pressure, weight and other risk factors will allow doctors to evaluate a patient's hypertension risk clinically. Our findings do show, however, that small vessel arteriolar changes play an important part in the development of hypertension, independent of previous blood pressure, weight, or weight change, and may therefore be potential targets for treatment or prevention.

Tien Wong associate professor

Centre for Eye Research Australia, University of Melbourne, 32 Gisborne Street, East Melbourne, VIC 3002, Australia twong@unimelb.edu.au

Anoop Shankar research associate Department of Ophthalmology, University of Wisconsin, Madison, WI 53726, USA

Competing interests: None declared.

1 Vasan RS, Larson MG, Leip EP, Kannel WB, Levy D. Assessment of frequency of progression to hypertension in non-hypertensive participants in the Framingham heart study: a cohort study Lancet 2001:358:1682-6.

\section{Man wins battle to keep receiving life support}

\section{Pro-choice living wills are essential}

Editor-Leslie Burke's High Court case shows how necessary it is today to develop extensively the concept of the pro-choice living will.

In the past, the typical living will (also known as an advance directive, an advance refusal, or an advance statement) only allowed patients to refuse medical interventions or treatments which were aimed at prolonging or sustaining life. Opponents of such living wills could condemn these documents as suicidally motivated refusals of medical treatment.
In 1999, when being interviewed by Clare Dyer, for the BMJ, I said that, "Of course (a living will) could be written to state that one wants to stay alive with life prolonging measures for as long as possible."

Recently, Friends At The End (11 Westbourne Gardens, Glasgow G12 9XD) produced a pro-choice living will, which can be used equally well by those who traditionally have not wanted life-prolonging care as well as by those people, like Mr Burke, who want medical treatment to be given to prolong their lives for as long as possible.

I believe all medical and nursing personnel should make a living will, setting an example for others to follow, because this could be of great value some day to their personal doctors, family, and friends.

Michael H K Irwin retired general practitioner Hove BN3 3EH

michael-hk.irwin@virgin.net

Competing interests: MHKI is a member of Council, Friends At The End, and Former Chairman, Voluntary Euthanasia Society (England and Wales).

1 Dyer O. Man wins battle to keep receiving life support. $B M$ 2004;329:309. (7 August.)

2 Dyer C. Euthanasia campaigner to stand in by-election BMJ 1999:319:1154.

\section{Doctors must always give patients best possible care}

EDITOR-Some will be appalled at the recent ruling in the case of Leslie Burke against the General Medical Council ${ }^{1}$ and see it as opening the floodgates to patients demanding all sorts of treatments that theoretically prolong life but are expensive and possibly dangerous, as well as undermining the specialist role of medical professionals in making expert decisions.

The emotive nature of feeding and hydration means that we, the doctors, may not use evidence as the basis for our clinical decisions and, as the Disability Rights Commission rightly points out, we risk using personal judgments based on factors such as quality of life. ${ }^{1}$ No doubt the GMC guidelines were created in good faith, but they make it possible for doctors to wield excessive paternalistic power and to leave the patient feeling vulnerable, as Mr Burke clearly felt himself to be.

Feeding and hydration should be kept separate from other medical treatment, or doctors should be careful to use the same yard sticks for implementing feeding and hydration as for any other treatment. Doctors must be seen to be making their decisions on the basis of fact and evidence as far as possible.

Studies show that feeding may not be helpful in cachexia-anorexia syndrome and dementia but has a role in stroke. ${ }^{2-4}$ Studies have also shown that clinicians are slow in making the assessments and initiating the treatment. ${ }^{5}$ Until more data on the role of feeding and hydration in different disease processes exist, thirst and hunger in a patient must be addressed as any other symptom.
Doctors' role is to treat patients safely and to the best of their ability, be the intent curative or palliative. Their role is not to prolong dying or save the state the burden of long term care for someone with a severe disability, however poor that person's quality of life is perceived to be.

Rosemarie Anthony-Pillai specialist registrar in palliative medicine

Sue Ryder Care-St John's Hospice,

Moggerhanger, Bedfordshire MK44 3RJ

roseap@doctors.org.uk

Competing interests: None declared.

1 Dyer O. Man wins battle to keep receiving life support. $B M$ J 2004;329:309. (7 August.)

2 Thomas DR. Distinguishing starvation from cachexia. Clin Geriatr Med 2002;18(4):883-91.

3 Sanders DS, Alan JA, Bardhan KD. Percutaneous endoscopic gastrostomy: an effective strategy for gastrostomy feeding in patients with dementia. Clin Med 2004;4:235-41

4 Bath PM, Bath FJ, Smithard DG. Interventions for dysphagia in acute stroke. Cochrane Database Syst Rev 2000;(2):CD000323

5 Rodrigue N, Cote R, Kirsch C, Germain C, Coutier C, Fraser R. Meeting the nutritional needs of patients with severe dysphagia following a stroke: an interdisciplinary approach. Axone 2002;23(3):31-7.

\section{Blood should be treated respectfully}

EDITOR-Eaton passed on a useful reminder from the chief medical officer on the hazards of blood transfusion. ${ }^{1}$ Transfusions should be rare events in elective general surgery, and each event should be discussed at the next clinical meeting. Even in the case of operations as complex as oesophagogastrectomy and abdominoperineal resection of the rectum, transfusion can be avoided nine times out of 10 . I also found that half the elective resections of abdominal aortic aneurysm could be safely done with a transfusion of 0 - 2 units.

The use of headlamp illumination, gentle saline irrigation, and when necessary magnification, provide optimal conditions for securing blood vessels before they are divided. The only problem is that operations take longer.

As an act of penitence I used to personally wipe away even a single drop of blood if spilt on the theatre floor, after completing the operation. It did not happen often but used to amuse the nurses, who no doubt sterilised the floor after I left.

I do not agree with the chief medical officer, however, that only consultants should order blood. Anyone with the membership of the Royal College of Surgeons or Royal College of Physicians is more than qualified to do this.

Roger H Armour honorary consultant surgeon (retired)

Lister Hospital, Stevenage, Hertfordshire SG1 4AB roger@rharmour.fsnet.co.uk

\section{Competing interests: None declared.}

1 Eaton L. Chief medical officer warns that many blood transfusions are unnecessary. BMJ 2004;329:308. (7 August.) 